\title{
Discriminated avoidance conditioning as a function of duration of intertrial interval and type of shock
}

GERALD B. BIEDERMAN

UNIVERSITY OF TORONTO

In a discriminated lever-press avoidance conditioning experiment, rats showed facilitation in avoidance learning under discontinuous shock $(.2 \mathrm{sec}$ on, $2 \mathrm{sec}$ off). Significant interactions were obtained between strain (Wistar and Sprague-Dawley) and intertrial interval durations (22.5, 45 and $90 \mathrm{sec}$ ) during shaping and training respectively.

Recent investigations have had considerable success in obtaining visual discriminated bar press avoidance conditioning in rats (D'Amato, Keller, \& Biederman, 1965; Biederman, D'Amato, \& Keller, 1964; D'Amato \& Fazzaro, 1966). These studies used optimal parameters of discontinuous US (shock). It seems likely that part of the inability of earlier experiments to obtain discriminated avoldance learning was due in some measure to the fear response to shock which is manifested by S's rigld posture or his continuous depression of the response lever (cf., Meyer, Cho, \& Wesemann, 1960; D'Amato \& Schiff, 1964).

Discontinuous shock is thought to promote generalization of the escape response to the preshock condition. That is, upon occasion $S$ finds himself pressing the bar during the "off" phase of the discontinuous shock cycle (Biederman et al, 1964).

The purpose of the present study was to provide another means by which the presumed fear reaction might be manipulated by varying the average durution of the intertrial interval (ITI). If the presentation of the US is critical in retarding avoidance conditioning the strategy of using longer ITIs might be expected to make such conditioning easier as the behavior associated with fear might well have a chance to dissipate.

In any event, increasing the interval between trials makes it more probable that random behavior will enable a frightened $S$ to remove himself from the bar. Bar holding in lever press avoidance is certainly a major factor in the interference with optimal avoidance conditioning.

It seemed desirable also to determine the importance of ITI in initial shaping trials which might play an Important role in determining the level of S's fear in subsequent training. This investigation afforded the further opportunity to study the effects of discontinuous shock on avoidance in interaction with varying duration of ITI.

\section{Subjeets}

The Ss were 90 Wistar rats supplied by Canadian Research Farms in Toronto, Ont., and 90 rats from Sprague-Dawley in Madison, Wis. All were male and approximately 90-120 days of age. Because of the unexpected low level of performance by Wistar rats the Sprague-Dawley strain was employed in a replication of the Wistar experiment.

Apparatus

The apparatus was similar to that used by Blederman et al (1964), and D'Amato et al (1965). Ss performed in either of two commercial two-bar Stinner boxes (Grason-Stadler) with the right bar removed. CS was provided by the illumination of three white jewel stimulus lights situated on the front wall of each chamber. Automated programming was provided by associated Grason-Stadler equipment. A duplicate but independent programming apparatus was used for each Skinner box. ITI was varied by exchanging tapes in the film-tape programmers associated with each Skinner box. The tapes were prepunched for VI 22.5, 45, or $90 \mathrm{sec}$. Masking white notse was delivered to each chamber throughout the training. Shock (US) was delivered via the floor bars in each sikinner box, by means of a grid-scrambler shock generator.

\section{Procedure}

Ninety Wistar rats were used in all conditions prior to the introduction of the 90 Sprague-Dawley Se to the experiment. The overall procedure was the same for each strain.

On Day 1, Ss were given 40 avoidance trials and were shaped (when necessary) to perform the escape response. CS was the lllumination of the stimulus lights. CS-US interval was $5 \mathrm{sec}$. If no response was made within this avoidance interval, a $1.0 \mathrm{~mA}$ shock was delivered until the escape response was made. After a response (and according to experimental group) an ITI followed. Ss were assigned randomly to one of three ITI groups, 22.5, 45, or 90 sec. During shaping US was continuous shock.

On Day 2, Ss were distributed by a counterbalanced arrangement into one of three ITI groups $(22.5,45$, or $90 \mathrm{sec}$ ) and into one of two shock groups (continuous or discontinuous). They were presented with 500 avoldance conditioning trials.

Within each strain the order in which the members of the experimental groups performed was random. The Ss were randomly distributed (within each of the two strains) 45 per group into one of two shock conditions, 30 per group into one of three Shaping-IT conditions, and 30 per group-into one of three Training-ITI conditions. Thus a 2 by 2 by 3 by 3 factorial design was constructed.

\section{Resulfs and Diseussion}

The dependent variable used in this study was percentage of avoldance responses over the last 400 training 
trials. This measure has been used by D'Amato et al (1965).

The overall results in terms of the experimental design may be seen in Fig. 1. It is clear once again that discontinuous shock enhances avoidance learning. Analysis of variance shows that the shock main effect is significant $(F=3.64$, df $=1 / 44, p<.05)$. What is not clear is the cause of the lower overall avoidance performance that was obtained in this study, considering that an equivalent standard conditioning apparatus was used and that the Sprague-Dawley strain was presumably identical with the Sprague-Dawley strain used in D'Amato \& Fazzaro (1966), where comparable discontinuous US intensities yielded a much higher level of avoidance in comparable ITI groups.

It is difficult to estimate the significance of strain on the overall amount of avoidance conditioning. Since the Wistar strain had performed relatively poorly compared with Ss in earlier studies (e.g., Biederman et al, 1964), we turned to the Sprague-Dawley animals. The strain main effect was not significant ( $F<1$ ), but interesting interactions were attributable to the combination of strain and ITI, as may be seen in Fig. 2. Brief ITI during both shaping and training apparently facilitated avoidance for Sprague-Dawley Ss, while longer ITI improved avoidance for Wistar Ss (Shaping-ITI by Strain, $\mathrm{F}=7.27, \mathrm{df}=2 / 144, \mathrm{p}<.005$; Training-ITI by Strain, $\mathrm{F}=$ 4.85 , df $=2 / 144$, $p<.01$ ). No other main effects or interactions achieved significance.

The results of this study call attention to the importance of ITI parameters during the early shaping trials and to the curious manner in which strain of $S$ influences avoidance conditioning. The ITI main effects (Shaping, $F=2.58, \mathrm{df}=2 / 144, \mathrm{p}<.10 ;$ Training, $F=1.47, \mathrm{df}=2 / 144$, $\mathrm{p}<.25)$ were attenuated through the ITI-strain interactions.

Any theoretical explanation of discriminated avoidance conditioning would do well to take strain characteristics into account in connection with fear states presumably produced by the characteristics of the situation. Theories holding that fear interferes with avoidance conditioning would receive experimental sup-

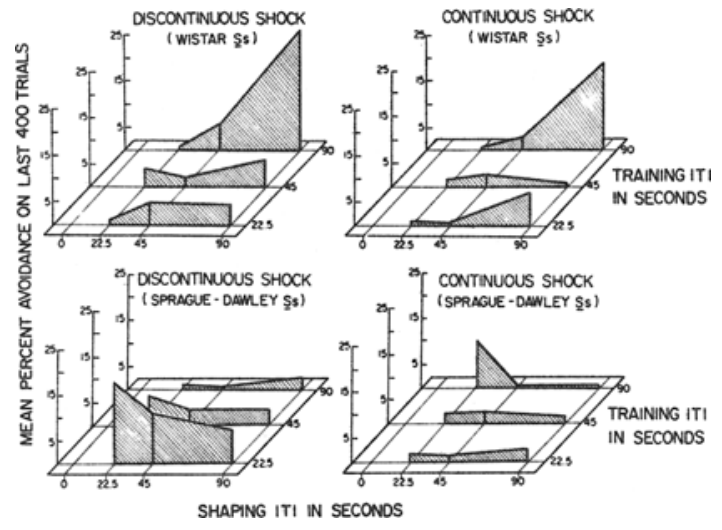

Fig. 1. Mean percent avoidance on last $\mathbf{4 0 0}$ training trials as a function of type of shock, strain, and ITI during shaping and training.

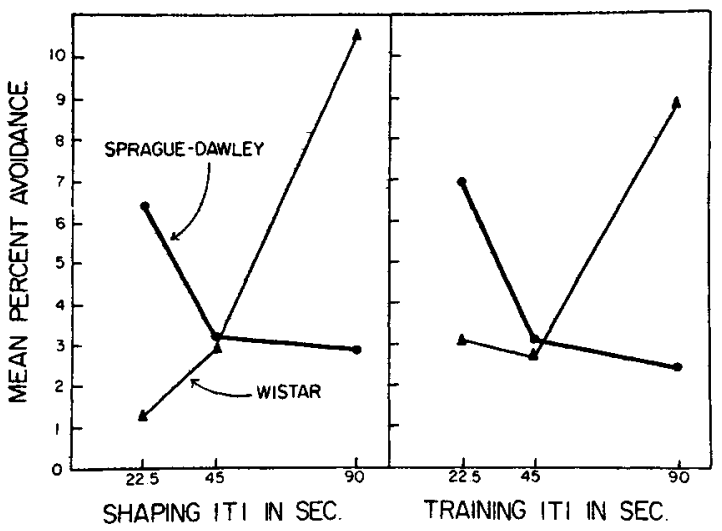

Fig. 2. Interactions between strain and ITI on mean percent avoidance.

port from the data provided by Wistar Ss. That is, the longer the ITI during shaping and training, the better the performance. Presumably fear has a chance to decrease as the ITI becomes longer. The explanation for the performance of the Sprague-Dawley animals is certainly not consistent with theory, nor do whatever small differences that exist between Sprague-Dawley and Wistar Ss readily explain the rather strong performance differences.

The present experiment does not logically permit a direct evaluation of the impact of strain, since this effect is confounded with experiment order, as Wistars preceded Sprague-Dawley Ss in actual experimentation. Operationally, the conditions under which the two strains performed were as similar as possible. Handling routines, feeding schedules, temperature, humidity, daynight cycle were identical for Wistar and SpragueDawley Ss. The experimental procedure was automated and the handling routine for placing Ss into the experimental chambers was simple and stereotyped. It seems highly improbable that any chance environmental difference could have produced such an effect on conditioning. Considering the levels of confidence reached in the Shaping-ITI by Strain and Training-ITI by Strain interactions ( $p<.005$ and .01 , respectively), the joint probability that a Type I error was made seems small. The theoretical structures which might today predict the results of this experiment are clearly not available. References

BIEDERMAN, G. B., D'AMATO, M. R., \& KELLER, D. M. Facilitation of discriminated avoidance learning by dissociation of CS and manipulandum. Psychon. Sci, 1964, 1, 229-230.

D'AMATO, M. R., \& FAZZARO, J. Discriminated lever-press avoidance learning as a function of type and intensity of shock. J. comp. physiol. Psychol, 1966, 61, 313-315.

D'AMATO, M. R., KELLER, D., \& BIEDERMAN, G. Discriminated avoidance learning as a function of parameters of discontinuous shock. J. exp. Psychol, 1965, 70, 543-548.

D'AMATO, M. R., \& SCHIFF, D. Long-term discriminated avoidance performance in the rat. J. comp. physiol Psychol, 1954, 57, 123-126.

MEYER, D. R., CHO, C., \& WESEMANN, A. F. On problems of conditioning discriminated lever-press avoidance responses. Psychol Rev., $1960,67,224-228$.

Note

1. This research was supported in part by NRC grant APA 185. The assistance of Miss M. Archer and Mr. G. Heighington is gratefully acknowledged. 